\title{
The Examination of the Effects of Land Use Development on the Balance of Mass Transit Ridership
}

\author{
Achara Limmonthol ${ }^{\mathrm{a}}$, Jittichai Rudjanakanoknad ${ }^{\mathrm{b},{ }^{*}}$, and Pongsun Bunditsakulchai ${ }^{\mathrm{c}}$ \\ Department of Civil Engineering, Faculty of Engineering, Chulalongkorn University, Bangkok 10330, \\ Thailand \\ E-mail:ajiejee_lmt@hotmail.com, bjittichai@hotmail.com (Corresponding author), cb.pongsun@gmail.com
}

\begin{abstract}
The balance of the origin-destination (O-D) ridership distribution is an essential characteristic of a sustainable transit system. However, the existing ridership patterns of transit system in many cities are still off-balance, leading to the inefficient utilization of available capacity. As a result, only one direction is overcrowded whereas the other is not. Many literatures suggest that the transit ridership distribution is generally affected by land use around stations due to the different rates of generated and attracted passengers during each period of time. Therefore, the objective of this study is to verify the effects of land use development according to the Transit Oriented Development (TOD) principle on the balance of the O-D ridership along the transit route, as measured by the discrepancies between the numbers of onboard passengers in stations along a single train line. This study has applied the modified Fluid Analogy Method to reflect the travel behavior of mass transit trip distribution. The results show that, to balance the O-D ridership along a linear and stand-alone transit route, the residential areas should be located near the terminal stations with the sub-residential areas in the interval to shorten the distance of home-based trips. The business areas should be densely situated in the middle of mass transit route, while the retail areas should be located dispersedly all along the route. This study has further applied a proposed model with a case study of MRT Blue Line in Thailand to verify the assumption that the location of the mixed-use project along MRT transit route has impacts on the balance of its ridership. This implication can be a guideline for integrating the mixed-use project development and the land use planning to achieve the sustainable transport in the overall perspective.
\end{abstract}

Keywords: Trip distribution, transit ridership, transit oriented development (TOD).

ENGINEERING JOURNAL Volume 24 Issue 2

Received 9 September 2019

Accepted 11 February 2020

Published 31 March 2020

Online at https://engj.org/

DOI:10.4186/ej.2020.24.2.1 


\section{Introduction}

One of the major problems of many transit agencies is the non-optimality of origin-destination (O-D) distribution that leads to the waste of available capacity and inefficient usability. The balance of ridership distribution along the transit route is a significant characteristic that supports the utmost utility of the transit system. From a transportation perspective, the problems of inefficient O-D distribution and the corresponding imbalance of ridership distribution can be witnessed through many aspects. For example, only one direction is crowded whereas another is not. Also, the crowds of passengers can only be seen in some particular sections of the route. Obviously, there are many benefits of balancing mass transit ridership distribution, such as gaining more operation profits of transit agency, enhancing more efficiency of the transit system as a whole, or reducing losses from an unoccupied capacity of the transit system.

Many studies claim that land use is one of the essential factors that affect trip generation and trip attraction, both of which can be interpreted as a fundamental behavior of O-D distribution, and hence have a considerable impact on the transit ridership $[1,2,3,4,5,6,7,8]$. Each type of land use creates different activities that influence the O-D distribution. The adjustment of land use development plan may therefore be a possible solution we can implement to improve the current pattern of O-D distribution and to alleviate the imbalance of transit ridership accordingly. Following the mentioned reasons, the transit system implementation and the urban planning should be worked on simultaneously. Usually, the development plan of these two factors, however, are to be improved separately rather than to be integrated.

The Office of Transport and Traffic Policy (OTP), which is under the Ministry of Transport of Thailand, has developed the Mass Rapid Transit Master Plan for Bangkok Metropolitan (M-Map) in 2010 to implement the mass rapid transit as planned from 2010 to 2029. The MRT Chaloem Ratchamongkhon Line (the MRT Blue Line) is one of the 10 routes in the M-Map. It is also the first subway MRT system in the downtown area of Bangkok. The line has been operative since July in 2004. The first phase of the MRT Blue Line consists of 18 stations with the distance of approximately 20 kilometres as shown in Fig. 1. Currently, there is an extended section being under construction. It is part of the project to extend the MRT Blue Line, according to the M-Map.

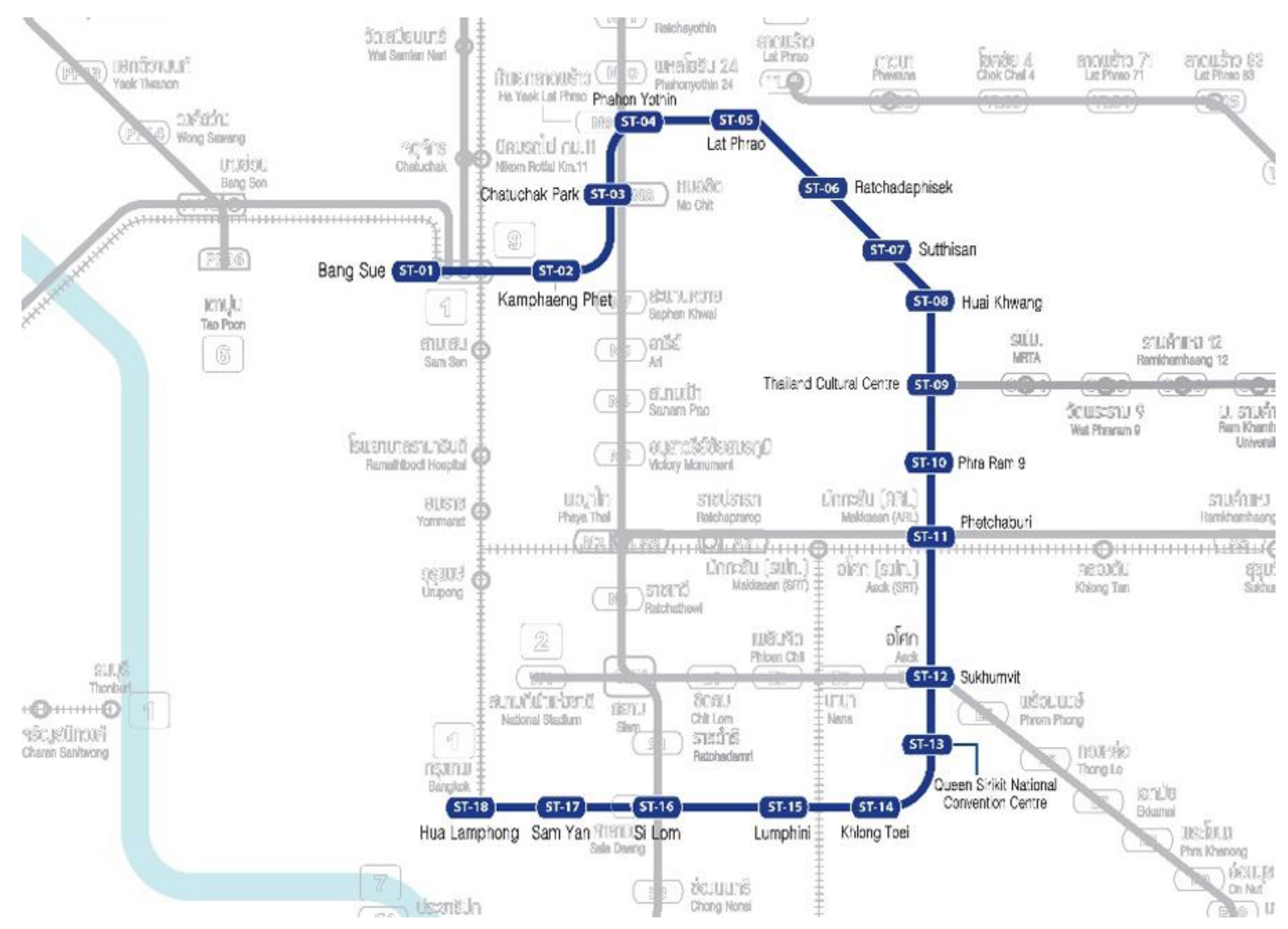

Fig. 1. The MRT Chaloem Ratchamongkhon Line. (modified from https://metro.bemplc.co.th).

The imbalance of ridership in Thailand is obvious in the MRT Blue Line. The ridership data records indicated that the inbound line is overcrowded in the morning hours whereas the other is not. The situation is reversed in the evening. The number of passengers also increases only in some sections of the route while many mixed-use projects are being developed along the MRT Blue Line route, such as the Sam Yan Mitrtown project, the One Bangkok project, the Dusit Thani - CPN project, the FYI center project, the PARQ project, the Bang Sue Grand Station project, etc. In addition, Thailand is now developing many MRT projects along the Master Plan and many real mixed- 
use projects are also being under development. We extremely realize that the problems as mentioned should be solved by planning the transit system, together with systematic land use along the public Transportation Oriented Development principle for the long-term unity growth. The planning of these projects, regarding the area of each usable type, the location of the project along the route, the mixed proportion of each type, should be considered to encourage the capability both for the transit system and the mixed-use project.

Nowadays, the land use regulations and transit system planning are developed individually. In Thailand, the Ministry of Transport (MOT) has more complete control over transportation agencies, while the Bangkok Metropolitan Administration (BMA) has the authority of urban planning within the province of Bangkok. However, both government agencies have no control over each other. This lack of consolidated authorization often results in the ineffective of urban development and transportation planning conformance. The integrated transportation and land use planning will hence be quite difficult [9]. Besides, the academic work on this issue is too insufficient to explain the relationship between the pattern of O-D distribution and the balance of transit ridership. In addition, an appropriate model for the MRT system, which is not the immediate mode of transportation between origin and destination, is necessary. The precise distribution model, which performs the behavior of MRT ridership distribution, should be formulated in order that the fundamental of the research can originate in the proper way. Moreover, there is also no research that integrate $\mathrm{O}$ $\mathrm{D}$ distribution and land use variables together. The integration of these two features would be the fundamental for transit route planning and land use regulations to make it supplement each other for the sustainable transportation and land use.

In this study, we apply the theoretical model that explains the patterns of O-D distribution to balance the mass transit ridership along the whole route by taking into account the effect of land use development on trip generation and trip attraction. The optimal proportion of land use types that help balancing the inbound and outbound ridership can accordingly be analyzed. The objective function is to minimize the variation of onboard ridership along the whole route, or simply stated, to maximize the number of passengers to reach the capacity of the train.

The content of this paper is structured as follows. In the next section, we describe the background of MRT Blue Line, which is the case study of balancing the mass transit ridership and review the related studies describing how land use impacts the transit ridership. Subsequently, we explain the reasons that support the suitability of the modified Fluid Analogy Method (FAM) and also describe the model formulation with the land use integration in detail. The solutions of ridership balancing schemes based on the modified FAM and the effects of mixed-use projects development on the ridership balance are examined afterwards. Finally, we interpret the results from the previous section as the guideline for land use allocation to support the ridership balance, and then make concluding remarks.

\section{Case Background}

\subsection{Subjective Concerns and Attitudes}

One of the striking characteristics of the MRT Blue Line ridership is that a great number of passengers always crowd into only one direction whereas the other is less so. Passengers always face long queues in only one direction of the route before they get on the train. Occasionally, densely-packed crowds of passengers can only be seen in some particular sections of the route. The onboard ridership (the number of passengers between any adjoining stations) have reached the maximum capacity of the train only in some sections. The unbalanced ridership problems as described are affected by land use arrangement, which concerns different activities caused by each type of land use. The land use along the MRT Blue Line route has been developed continuously in order that such management can help get more passengers to use the system. However, the lack of planning in land use development is an important factor of the imbalance of ridership.

The characteristics of the MRT Blue Line ridership as mentioned above are the non-optimality of origindestination (O-D) distribution, the waste of available capacity and the inefficient usability of the system. These problems are the obstacles that deter the maximum utilization. Balancing the mass transit ridership distribution not only makes a transit agency gain more operational profits, it also enhances the productivity of the transit system as a whole, whereby it reduces losses from the unoccupied capacity of the system.

\subsection{Impacts of Land Use Characteristics}

The impacts of urban form on travel demands have been analyzed in many literatures. The urban form impacts on travel demand are verified how it facilitates the design of urban development strategies of travel demand management and determined how improving the travel efficiency affects new urban planning paradigms. The result shows that an increase of the density of land use will trigger trip generation rate and reduce private-mode choice. On the contrary, balancing mixed land use would reduce mass transit trip generation rate but increase private-mode choice [10]. The urban-form factors are related to the land use management in terms of density (residential density, building density and employment density) and diversity (type-mix, housing-job, housingretail, retail-job, land use entropy index). Urban designs also have significant impacts on travel demands. The impacts of land use on public transport ridership are investigated through three different multivariate predictive models. The study shows that the prediction of ridership through a set of criterions using the decision tree is the 
best-fit model [11]. The algorithm for the decision tree model is designed by splitting the data samples with a critical value at each tree node into sub-branches. This algorithm allows the decision tree model to perform best in terms of good predictive accuracy, generality, computational efficiency, and interpretability.

The characteristics of land use and urban form influencing the transit ridership would be considered in terms of compact, density, or mixed-use developments, level of automobile access, pedestrian network, residential density, size of downtown, multi-family housing, and the distance from stations to downtown areas [5, 6]. Land use policies, such as the limitation of land use density, the principal activities of a development, the minimum lot size requirements, affect mode choices of the transit user both in higher or lower conducive transit system demands [12].

\subsection{Trip Generation and Trip Attraction Rates of Land Use}

Each type of land use has different trip generation and attraction levels as suggested in previous studies and surveys through several institutes and reports. The trip generation and attraction rates are typically derived from the observed data through the regression analysis. The trip generation rates for different land use types are estimated by collecting data on vehicle trip rates and focusing on single-use, vehicle-oriented trip rates in suburban sites of the United States [13]. Moreover, this report is updated periodically with the new land use descriptions, trip generation rates, equations, and data plots. The number of trips from/to a particular site or area, according to the inventory of land uses, is estimated as trip generation and attraction rates. It can also be calculated as daily trips or peak-hour trips for a particular site, depending on the type of land use, and expressed as vehicle trips or person trips, such as the amount of trips per employee, the amount of trips per unit land area [14]. The information of vehicular traffic generated by different land uses are collected into a trip generation manual. The trip generation rate including the percentage of AM and PM peak-hour trips and the proportion of trips entering and exiting during the peak hours are summarized [15].

\section{Methodology of Ridership Balancing Scheme}

The objective of this study is to determine the pattern of land use allocation that leads to the balance of mass transit ridership along the whole route for both inbound and outbound trips. Firstly, let us describe the structure of railway alignment in which we assume to be a linear system train line (no connection with any other lines) as shown in Fig. 2. The objective function is formulated as to minimize the variations of onboard passengers between any adjoining stations $i$ and $j$, where $j=i+1$ for an outbound direction and $j=i-1$ for an inbound direction as shown in Eq. (1).

$$
\begin{aligned}
& \min \operatorname{Var}\left(\mathrm{R}_{12}, \ldots, \mathrm{R}_{i, i+1}, \ldots, \mathrm{R}_{N-1, N},\right. \\
& \left.\mathrm{R}_{N, N-1}, \ldots, \mathrm{R}_{i, i-1}, \ldots, \mathrm{R}_{21}\right) \\
& \quad \operatorname{or} \\
& \min \operatorname{Var}\left(\mathrm{R}_{i j}\right), \quad \forall|i-j|=1 ; i, j \in\{1,2, \ldots, N\}
\end{aligned}
$$

$R_{i j}$ is the number of onboard passengers between station $i$ and $j$ and represents the ridership between each pair of stations (unit: percent).

Before moving on to other features of our model structure, let us clarify the 'unit' of the number of passengers used throughout this paper. Considering a single and stand-alone linear system train line, let be the total (or maximum) number of passengers currently using this transit system (unit: person). We can thus analyze the number of passengers boarding or alighting at any station, the number of onboard passengers between each pair of stations and so forth as the 'percentage' of the whole population for the convenient of result interpretation.

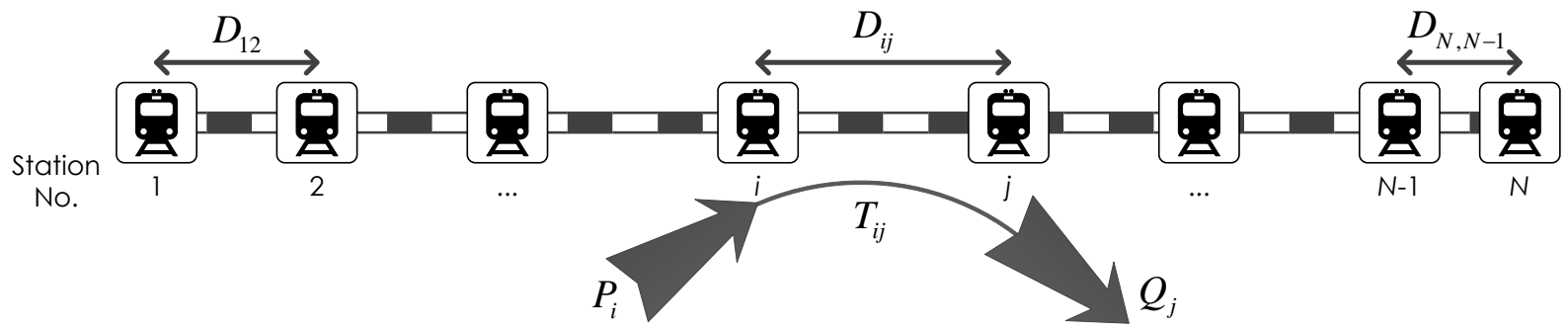

Fig. 2. Structure of railway alignment.

Let us define other variables used in the model as follows.

$P_{i}$ is the percentage of passengers boarding at the station $i$ (unit: percent),
$Q_{j}$ is the percentage of passengers alighting at the station $j$ (unit: percent),

$T_{i j}$ is the percentage of passengers boarding at the station $i$ and alighting at the station $j$ (unit: percent), 
$D_{i j}$ is the distance between stations $i$ and $j$ (unit: kilometre),

$N$ is the total number of stations along the whole transit route (unit: station), and

$\bar{C}$ is the maximum capacity of the train (unit: percent).

The most common functional form of trip distribution for travel demand forecasting is a 'Gravity Model' which is based theoretically on Newton's law of attraction which assumes that the trips produced at an origin and attracted to a destination are directly proportional to the total trips produced at the origin and those attracted to the destination. The deterrence function of the gravity model is formulated as a function of distance, travel time, travel cost, and other interaction factors between each O-D pair [16, 17]. It is extensively applied to estimate the patterns of trip distribution, e.g. the intraurban traffic of the town networks [18], the commuting flow between municipalities [19].

However, in our previous study [20], the two trip distribution models - the gravity model and the Modified Fluid Analogy Method - are compared in several aspects and it has been found that the Modified Fluid Analogy Method (the modified FAM) shows more distinctive and realistic performance to express the characteristic of ridership distribution. To summarize our findings, the balancing results of transit ridership based on the modified FAM and the gravity model are shown in Fig. 3, where the $\mathrm{X}$-axis is number of station and $\mathrm{Y}$-axis is amount of passengers. In short, the main supporting reasons for the suitability of the modified FAM for describing the urban transit behaviour are summarized as follows.
(1) The modified FAM can describe the nature of catchment area around both terminal stations where the number of passengers is generally higher than the number of passengers boarding at the in-between stations.

(2) The overall patterns of boarding passenger distribution at each station in case of the modified FAM are not much altered by the variation in the value of the degree of deterrence $(\lambda)$. The modified FAM, therefore, is robust and reliable when put into practice.

(3) The modified FAM exposes the fact that the number of passengers in a mass transit system during peak hours always increases drastically only in one direction while the other direction is not congested, obviously seen in the difference between the number of boarding and alighting passengers at each station.

(4) The modified FAM has the additive functional form of fixed and linearly variable terms. In the context of mass transit, any passenger boarding the train at any station is abiding some fixed cost, e.g., the time loss during ticket purchasing process and waiting time for the train. On the other hand, when deciding whether to leave the train or to remain boarding until the next station, a passenger usually faces the additional cost in terms of time loss (value of time) linearly proportional to the travelling distance. The combination of these two costs is suggested by the functional form of the modified FAM.

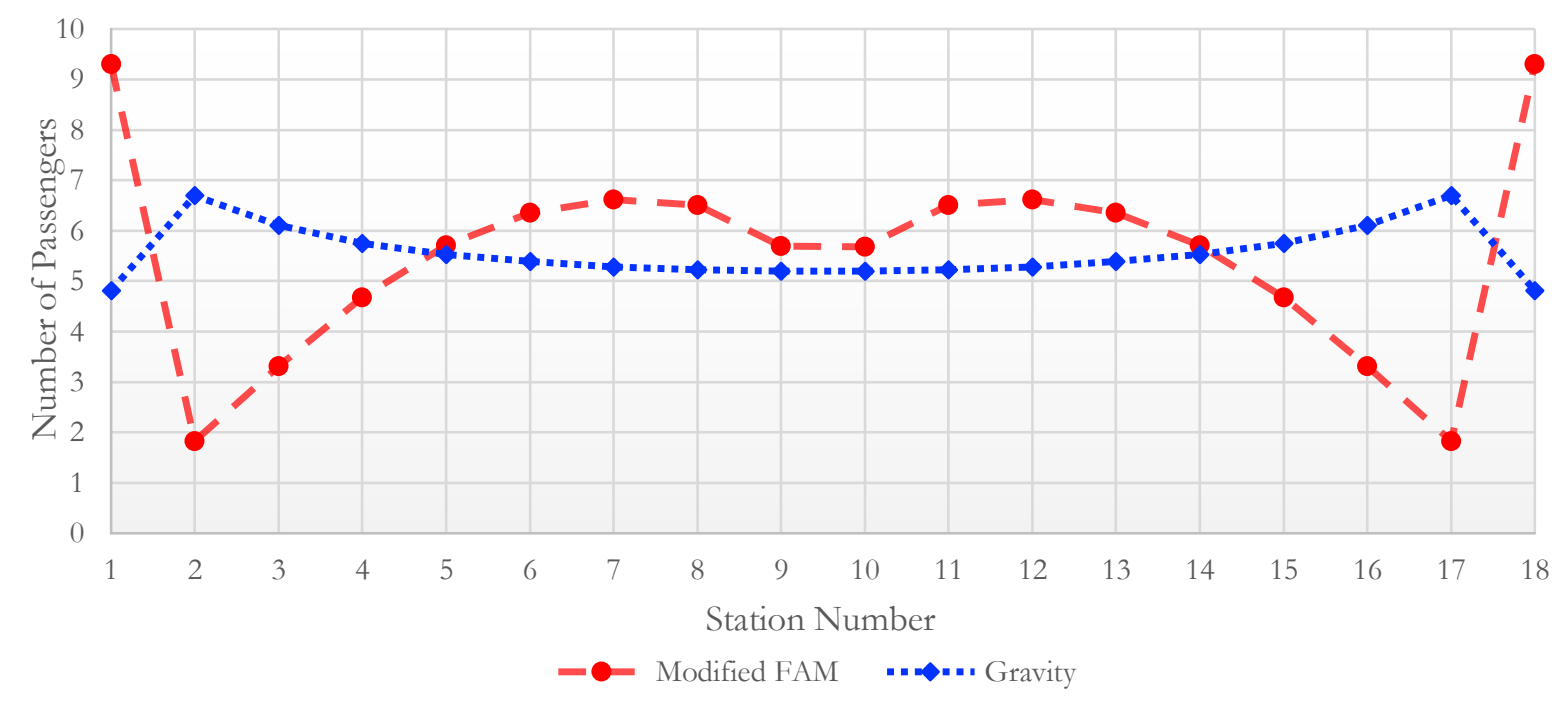

Fig. 3. The number of passengers boarding at each station as a solution of balancing transit ridership based on the modified FAM and the gravity model (Unit: percent).

\subsection{Model Formulation of Modified Fluid Analogy Method}

There are a series of previous researches that aimed to estimate O-D flows in the absence of historical O-D matrices. Those models are built based on the concept of Fluid Analogy Method (FAM) originally applied for estimating bus passenger O-D trips $[21,22]$. However, the adaptability problems of the bus-passenger version as a static model in which space-dimension could only be 
realized afterward. The FAM is revised with the explicit time-dimension parameters using the structure of multilayer matrices [23]. The research is extended to verify the model performance by empirical data of flow counts on freeway ramps and the estimation outcomes that show acceptable errors and calculation efficiency [24].

In this section, we further applied the FAM concept with the transit O-D ridership determination. Given the variable explanation, together with the objective function stated above, we formulate the boarding and alighting behaviour of passengers based on a fluid flow through a cone-shaped pipeline whose diameter is varying according to distance, as shown in Fig. 4. The possibility that the passengers will alight from the train is proportionally increasing by the size of the diameter of the pipeline. It is similar to the volume flow rate. The number of passengers boarding at the station $i$ and alight at the station $j$ is determined by Eq. (2).

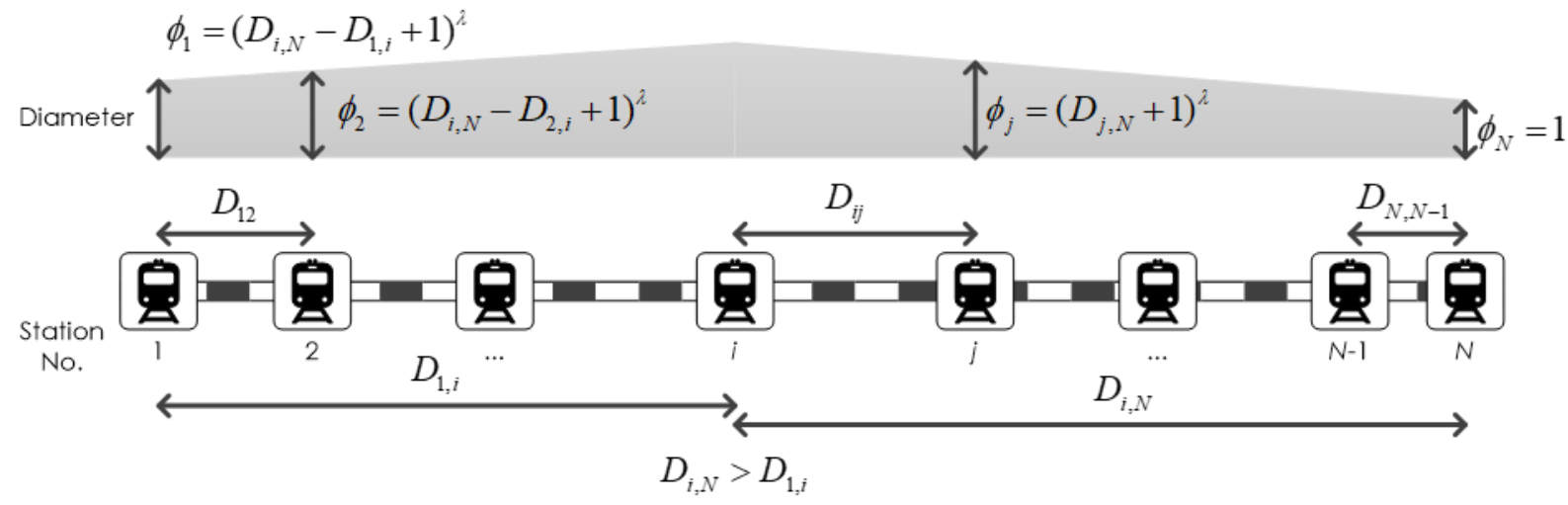

Fig 4. Cone-shaped pipeline and the Modified Fluid Analogy Method.

$$
T_{i j}=\left(\frac{\left(D_{\max , i}-|i-j|+1\right)^{\lambda}}{\sum_{j}\left(D_{\max , i}-|i-j|+1\right)^{\lambda}}\right) \times P_{i}
$$
follows:

(1) The diameter of the pipeline is set to be equal to 1 at the farthest station,

(2) The diameter is increasing in relation to the distance when approaching the particular station $i$ and decreasing when passing through, and

(3) The distance between all stations are set to be equal to $D$

The maximum distance, $D_{\max , i}$, that any passenger can plausibly travel from the station $i$ within the same transit route, is calculated by Eq. (3).

$$
D_{\max , i}=\max \{N-i, i-1\} \times D
$$

The term $D_{\max , i}-|i-j|+1$ defines the size of the diameter at the station $j$ when considering the passengers boarding from the station $i$. $\lambda$ explains the acceleration rate by which the size of the diameter increases in relation to the distance from the farthest station. The number of passengers boarding between the stations $i$ and $j$ can be determined by Eq. (4) for the outbound direction and Eq. (5) for the inbound direction. Eq. (6) describes the passenger flow conservation constraint, the equivalence between the summation of boarding and alighting passengers from all stations and the total population (or 100 percent) of passengers within the transit route. Eq. (7) states that the ridership between any adjoining stations $i$ and $j$ must not exceed the capacity of the train.

$$
\begin{gathered}
\mathrm{R}_{i, i+1}=\sum_{k=1}^{i} \sum_{j=i+1}^{N} T_{k j}, \forall i \in\{1,2, \ldots, N-1\} \\
\mathrm{R}_{i, i-1}=\sum_{k=i}^{N} \sum_{j=1}^{i-1} T_{k j}, \forall i \in\{2, \ldots, N\} \\
\sum_{i} \sum_{j} T_{i j}=\sum_{i} P_{i}=\sum_{j} Q_{j}=100 \\
\mathrm{R}_{i j} \leq \bar{C}
\end{gathered}
$$

Therefore, the system of non-linear equations defined by the objective Eq. (1) and constraints Eq. (2) - (7) is used to solve for the optimal number of passengers boarding at the station $i$, which is the only endogenous variable for this optimization problem, $P_{i}$.

Referring to our previous research [20], the performances of (the degree of exponent) are compared by varying values at $1,1.5$, and 2 . The result shows that the higher degree of exponent signifies the case that any passenger has a lower probability to travel a long-distance trip than a short-distance one. As a result, the higher degree of exponent is more indicative of the characteristic of the inner-city train line where people tend to have a short trip for shopping or commercial purposes. In the meantime, the lower degree of exponent is used in a longer commuting train line where people in suburban areas take 
a long trip to work and study in the CBD. The degree of exponent at 2 is chosen to apply to the modified FAM in this study.

The modified FAM is further elaborated to theorize a relationship between land use and O-D distribution, which is subject to the relevant constraints regarding land use characteristics. In addition, the system of non-linear equations is solved for the optimal solution under a given set of exogenous variables. The results will be discussed later in the next section.

\subsection{Application of the Modified Fluid Analogy Method with Land Use}

The land use characteristic is one of the external factors that affect transit demands, as referred from the literature review. To reflect this characteristic, the modified FAM must further be developed to cope with a land use allocation problem in order to determine which proportion of each type of land use should be allocated around the mass transit station along the route. It thus can prompt the least variance in the number of onboard passengers to enhance the efficiency of the overall system through the more balanced ridership.

To apply the modified FAM to deal with land use consideration, the additional constraints regarding types of land use and their properties must be included. Let $K$ be the number of types of land use within the study area (unit: type) and $\bar{A}_{k}$ be the total area of land use type $k=1,2, \ldots, K$ (unit: square metre). By adding up the area of every type of land use together, the result must equal to the total coverage area of the whole transit route $(\bar{A})$ as shown in Eq. (8).

$$
\sum_{k} \bar{A}_{k}=\bar{A}
$$

For a single linear transit line, the total coverage area can approximately be determined by multiplying the number of stations, $N$, with the square of the walkable distance to the station, $r$, or $N_{r^{2}}$. However, we may need to exclude the public areas (street, railway) and abandoned areas from $N_{r^{2}}$ to determine the accurate total coverage area that can generate/attract travel demands.

As explained earlier, each land use type has different properties regarding the trip generation rate and trip attraction rate. To simplify the interpretation of results, let us define the rate of trip generation/trip attraction for each land use type as the 'percentage' of total passengers currently using this transit system generated/attracted by a unit area of each land use type. Let $\alpha$ be the rate of trip generation for the land use type (unit: percentage of total passenger/square metre) and $\beta$ be the rate of trip attraction for the land use type (unit: percentage of total passenger/square metre). For a specific period of time, such as during the morning or evening peak hours, the conservation rules of the total number (100 percent) of passengers within the whole coverage area of the transit route can be described as shown in Eq. (9).

$$
\sum_{k} \alpha_{k} \bar{A}_{k}=\sum_{k} \beta_{k} \bar{A}_{k}=100
$$

Therefore, the only endogenous variable in our model is defined as the area of land use type $k$ within the catchment area surrounding the station $i, A_{i k}$, (unit: square metre). The underlying mechanism is that the number of trips generated and attracted by all types of land use around a particular station can be expressed as a function of $A_{i k}$ as shown in Eq. (10) and (11) respectively.

$$
\begin{aligned}
& P_{i}=\sum_{k} \alpha_{k} A_{i k} \\
& Q_{i}=\sum_{k} \beta_{k} A_{i k}
\end{aligned}
$$

Another constraint described by Eq. (12) specifies that the allocation of a specific land use type over all stations must be limited to the target of the total area of that type. This constraint is prevailing in the real practice of land use development since developers should have the aimed target of the total area in their strategic plan corresponding to the activity types and purposes of the development of land within their jurisdictions.

$$
\sum_{i} A_{i k}=\bar{A}_{k}
$$

The system of non-linear equations defined by the objective Eq. (1) and all constraints in Eq. (2) - (12) completes the mathematic optimization problem to solve for the optimal area of each land use type surrounding the station $i, A_{i k}$, under a given set of exogenous variables. However, as total coverage area is a constant in this model, our results of optimization problem can be shown as the percentage of total coverage area for the simplicity of interpreting them.

\section{Ridership Balancing through Land Use Development}

In this section, we will utilize the modified FAM for a land use allocation problem to determine which proportion of each land use type should be allocated around the mass transit station along the route. The application of this model and its achievements are intended as the guideline for the sustainable development of land use and mass transit development simultaneously.

\subsection{Model Application with Land Use Consideration}

The model formulation as indicated in the previous section shows that the only endogenous variable for this optimization problem is the area of each land use type surrounding the station $i$. However, we need to specify the value of exogenous variables in the model as follows. 
The total number of stations in the whole transit route, $N$, is specified into 5 cases - 6, 9, 12, 15, 18 stations. The distance between adjoining stations that are assumed to be distributed evenly, $D$, is set to be 1 kilometre for the simplicity of calculation, although it can have any value and does not have any effect on the solutions. Moreover, this 'one-kilometre' reflects the coverage area, walkable distance, and the average distance between adjoining stations. The degree of exponent, $\lambda$, is 2 , as the results of the previous research show that the higher degree of exponent is more indicative of the characteristic of the inner-city train line. The total type of land use in the studied area, $K$, is set to be 3 types $-k=1$ for business type, $k=2$ for retail use, and $k=3$ for residential purpose. Here, the total area is set to be 100 percent and equally apportioned among three types of land use. Again, this setting is convenient when we converted the results into practical use.

The number of generated/attracted trips of each type of land use in the morning peak hour is defined in Table 1. Most trips in the morning hour are attracted to the business areas according to working purposes, whereas most trips are generated from the residential areas. The trips generated from and attracted to retail activities are assumed to be at an equal rate. Although this apportionment refers to the trip rates for the morning hour, these trip rates can also be applied to the evening peak hours by reversing the number of boarding and alighting passengers. We can then calculate the rate of trip generation, and the rate of trip attraction, from the percentage of generated and attracted trips as shown in Table 1, under the assumption that each type of land use generates/attracts constant trips during a specific period of time. Therefore, the values of $\alpha_{k}$ and $\beta_{k}$ are varied depending upon the area of each type of land use available in the system.

The results of an optimal land use allocation for the balanced ridership with a modified FAM model are shown in Fig. 5. When the number of stations is still low in the case of 6 stations, land uses around the terminal station are sparse and almost equally divided between residential and retail purposes. At the same time, the area around the central stations is densely packed with not only the business land but also with the residential and retail land, as shown in Fig. 5(a). The underlying reason is the shape of boarding passenger distribution, which is a concave curve only in the case of 6 stations. Therefore, high trip generation rates are required in the middle of the transit line and a large portion of residential and retail areas are hence accumulated there.

When the number of stations is growing, however, the pattern of land use distribution will look more similar. The residential areas are accumulated at both ends and the center of the transit line, the retail areas are consistently spreading along the whole line, and the business area is intensely concentrated in the CBD of the city, as can be verified in Fig. 5(b) and 5(c). This pattern represents the concept of the newly developed 'compact city with a single CBD', where the residential areas are located in the outskirts while a number of business enterprises, head offices and educational institutes are peaked at the central area.

Finally, when the number of stations is large enough as it represents a big city, the city will contain two layers of residential zone. The outer residential zone is located at both ends of the transit line, while the inner zone is located closer to the CBD than the terminal stations - as indicated by the station no. 6-8 and no. 11-13 in Fig. 5(e). This inner residential zone is functioning like a satellite city where not only residential use but also large-scaled shopping centers, educational institutes and industrial parks are also located here as part of a mixed-use urban development.

The optimal numbers of boarding passengers in the original modified FAM and those derived from the modified FAM for the land use allocation problem are compared for the case of $6,9,12,15$ and 18 stations as shown in Table 2 . The results reveal that the solutions are not necessarily equivalent since the additional constraints of land use allocation scheme reduce the domain space of endogenous variables to search for an optimal solution. Table 2 also indicates that when the number of stations is not large, the solutions of two problems are completely matching each other. However, when the number of stations becomes bigger, the variance of ridership from the land use allocation problem is inferior to the one from the original O-D distribution problem. Moreover, the exogenous variables also play a crucial role here. Especially, the total area of each land use type represents the upper bound of the endogenous variable - the allocated area of each type of land use around each station. Therefore, the sensitivity analysis may be necessary to test the robustness of simulation results. In addition, the investigation for the observed data of trip generation and trip attraction rate is also essential when putting our model in real practice. Nevertheless, the results presented here could be used as the guideline for land use development planning in order to enhance the usability of the mass transit system.

Table 1. The number of generated/attracted trips of each type of land use in the morning peak hour. (Unit: percentage of total passenger/square metre).

\begin{tabular}{lccc}
\hline \hline & Business & Retail & Residential \\
\hline \hline The number of generated trips & 5 & 15 & 80 \\
\hline The number of attracted trips & 80 & 15 & 5 \\
\hline
\end{tabular}




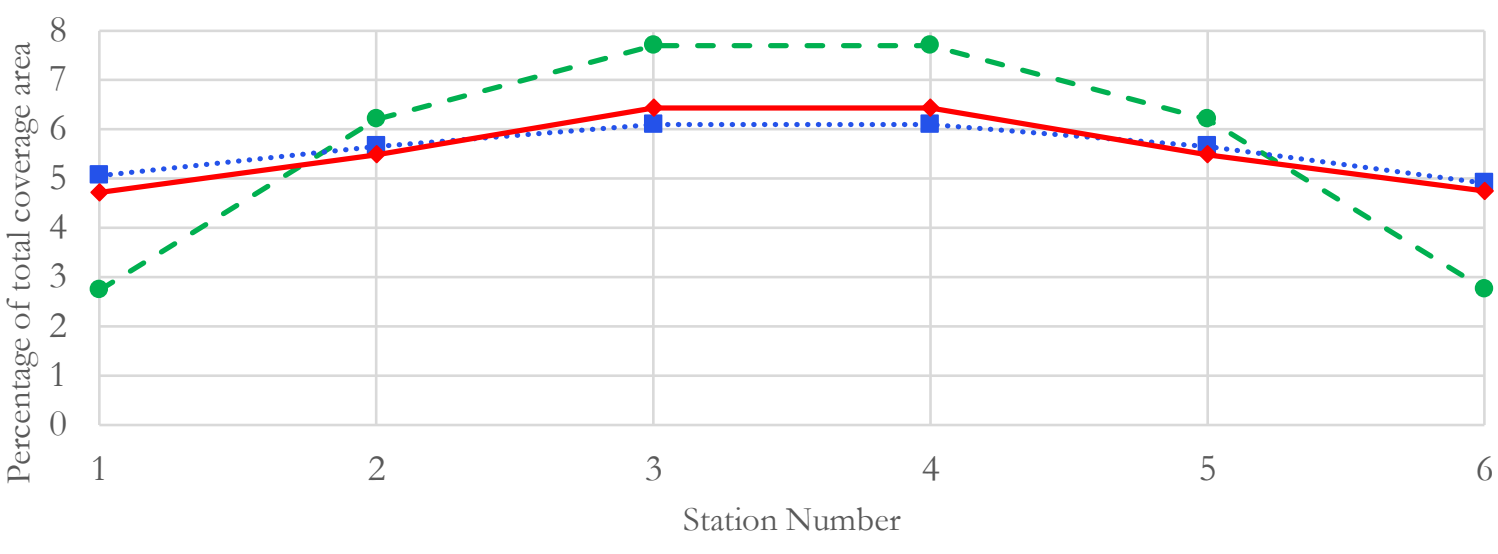

- - Business …… Retail $\longrightarrow$ Residential

(a)

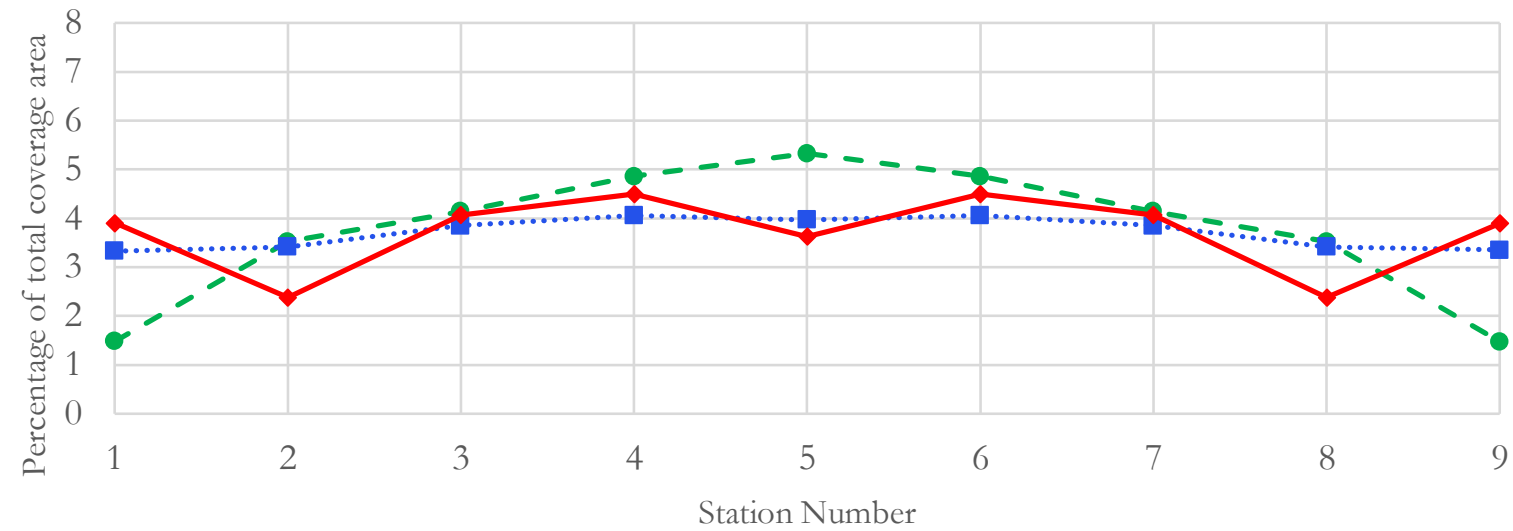

- - Business …… Retail $\longrightarrow$ Residential

(b)

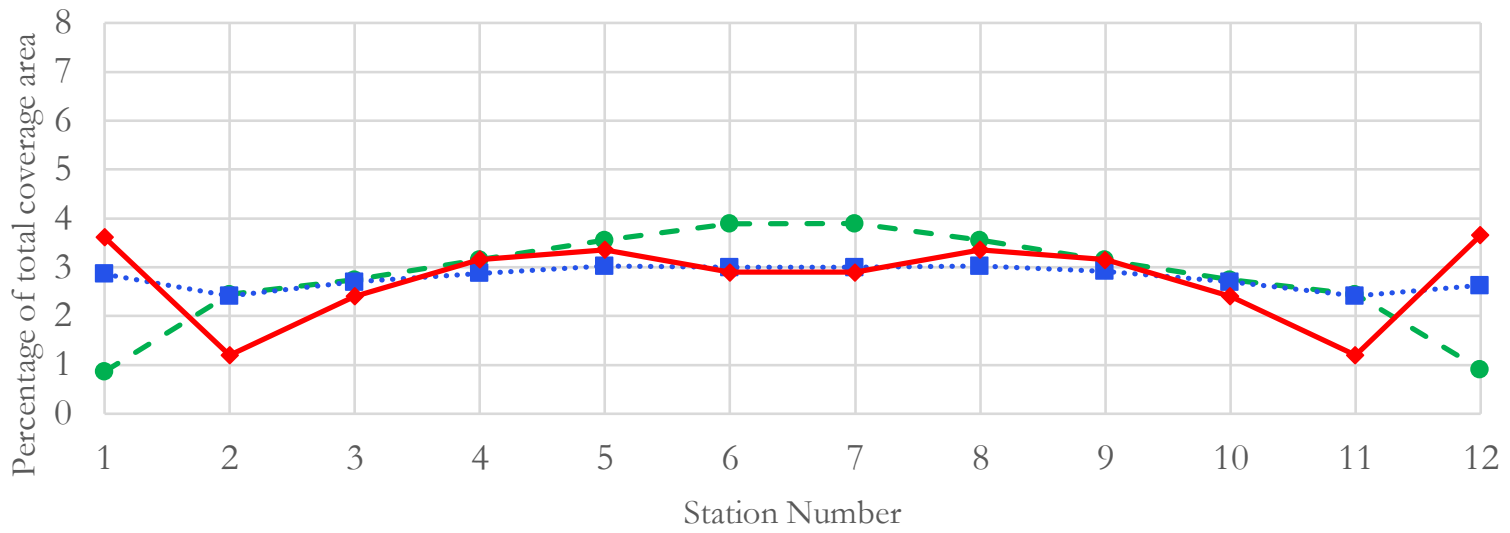

- - Business $\cdots \cdot$.... Retail $\longrightarrow$ Residential

(c) 


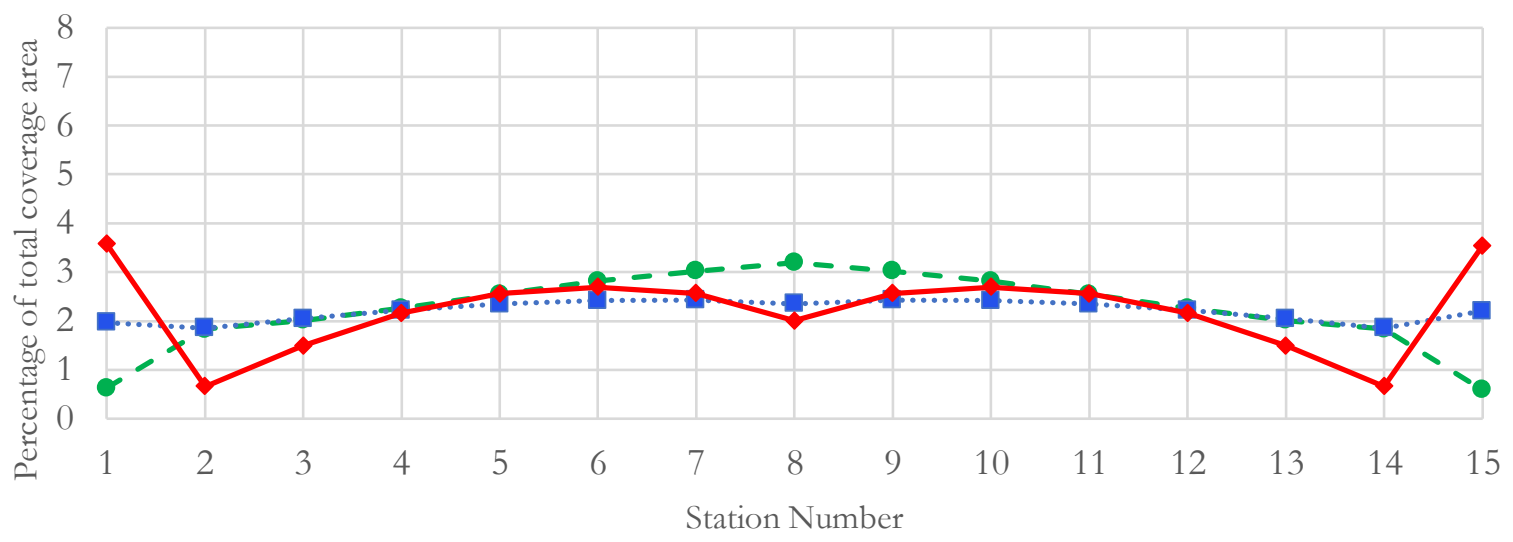

- - Business $\quad \cdots \cdot$.... Retail $\longrightarrow$ Residential

(d)

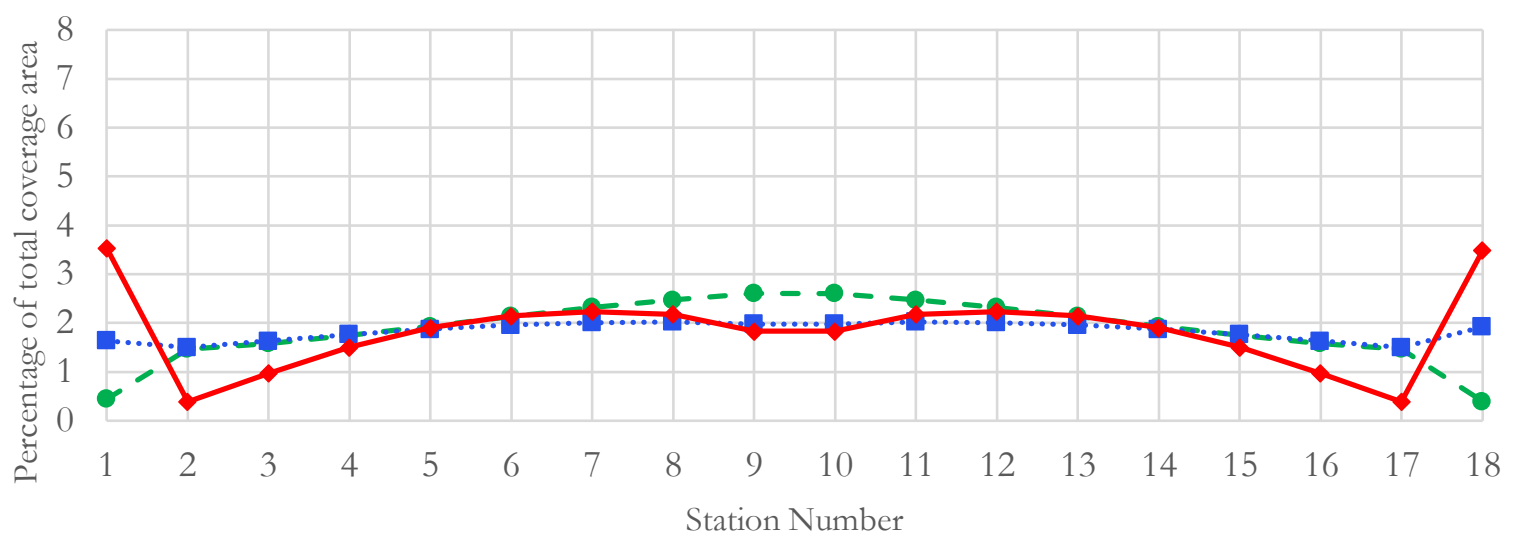

- - Business $\quad \cdots \cdot$.... Retail $\longrightarrow$ Residential

(e)

Fig. 5. Allocation of each land use type to balance O-D ridership with the modified FAM: (a) 6 stations, (b) 9 stations, (c) 12 stations, (d) 15 stations, (e) 18 stations (Unit: percentage of total coverage area). 
Table 2. Comparison of Ridership Balancing Results (Unit: percent).

\begin{tabular}{|c|c|c|c|c|c|c|c|c|c|c|}
\hline \multirow{3}{*}{$\begin{array}{c}\text { Station } \\
\text { No. }\end{array}$} & \multicolumn{10}{|c|}{ The percentage of boarding passengers } \\
\hline & \multicolumn{2}{|c|}{6 stations } & \multicolumn{2}{|c|}{9 stations } & \multicolumn{2}{|c|}{12 stations } & \multicolumn{2}{|c|}{15 stations } & \multicolumn{2}{|c|}{18 stations } \\
\hline & $A^{*}$ & $\mathrm{~B}^{* *}$ & $\mathrm{~A}^{*}$ & $\mathrm{~B}^{* *}$ & $\mathrm{~A}^{*}$ & $\mathrm{~B}^{* *}$ & $\mathrm{~A}^{*}$ & $\mathrm{~B}^{* *}$ & $\mathrm{~A}^{*}$ & $\mathrm{~B}^{* *}$ \\
\hline 1 & 14.01 & 14.02 & 111.09 & 111.09 & 10.09 & 9.34 & 9.57 & 7.56 & 9.30 & 6.40 \\
\hline 2 & 16.64 & 16.64 & 7.78 & 7.78 & 4.33 & 5.12 & 2.69 & 4.78 & 1.83 & 4.80 \\
\hline 3 & 19.34 & 19.34 & 12.13 & 12.13 & 7.40 & 7.44 & 4.80 & 4.84 & 3.31 & 3.35 \\
\hline 4 & 19.34 & 19.34 & 13.35 & 13.35 & 9.34 & 9.33 & 6.51 & 6.54 & 4.68 & 4.69 \\
\hline 5 & 16.64 & 16.64 & 11.30 & 11.30 & 9.96 & 9.96 & 7.58 & 7.58 & 5.71 & 5.73 \\
\hline 6 & 14.01 & 14.02 & 13.35 & 13.35 & 8.88 & 8.82 & 7.98 & 7.95 & 6.36 & 6.35 \\
\hline 7 & & & 12.13 & 12.13 & 8.89 & 8.83 & 7.69 & 7.64 & 6.62 & 6.60 \\
\hline 8 & & & 7.78 & 7.78 & 9.95 & 9.94 & 6.36 & 6.22 & 6.51 & 6.46 \\
\hline 9 & & & 11.09 & 11.09 & 9.35 & 9.37 & 7.69 & 7.64 & 5.69 & 5.58 \\
\hline 10 & & & & & 7.40 & 7.38 & 7.97 & 7.95 & 5.69 & 5.59 \\
\hline 11 & & & & & 4.33 & 5.16 & 7.57 & 7.58 & 6.50 & 6.45 \\
\hline 12 & & & & & 10.09 & 9.32 & 6.52 & 6.54 & 6.62 & 6.60 \\
\hline 13 & & & & & & & 4.80 & 4.85 & 6.36 & 6.37 \\
\hline 14 & & & & & & & 2.69 & 4.78 & 5.71 & 5.73 \\
\hline 15 & & & & & & & 9.57 & 7.56 & 4.68 & 4.72 \\
\hline 16 & & & & & & & & & 3.31 & 3.93 \\
\hline 17 & & & & & & & & & 1.83 & 4.26 \\
\hline 18 & & & & & & & & & 9.30 & 6.38 \\
\hline Variance & 10.36 & 10.36 & 11.01 & 11.01 & 10.55 & 10.60 & 10.29 & 10.58 & 10.03 & 10.53 \\
\hline
\end{tabular}

Note: $A^{*}$ - The original modified FAM,

$\mathrm{B}^{* *}$ - The modified FAM with land use consideration.

\subsection{The MRT Case Study of Thailand and the Land Use Allocation on Different Scenarios}

In this section, we further apply the modified FAM model to evaluate the effects of land use allocation on the ridership of the existing MRT project in Thailand (Chaloem Ratchamongkhon Line - MRT Blue Line). As mentioned earlier, the MRT Blue Line has a problem of unbalanced ridership. Therefore, this application will lead to a recommended guideline for the project development (real estate development, land sub-division, land consolidation) along the MRT route.

Firstly, the imbalance of ridership in the MRT Blue Line is empirically shown in Fig. 6 by comparing to the optimal solution derived from the modified FAM. If we use the Mean Absolute Percent Error (MAPE) to indicate the percentage deviation of the number of boarding passengers at each station from the existing situation, the MAPE of the optimal solution is $97.90 \%$. This indicator suggests that the whole population along the MRT Blue Line needs to be reallocated in order to move toward the optimal ridership balance.

In this particular case study, the value of exogenous variables should be specified in accord with the characteristics of the mass transit MRT Blue Line to make it more practical. However, some of them are set to be the same as shown previously and are summarized here again as follows. The distance between the adjoining stations, $D_{i j}$, is assumed to be distributed evenly at one kilometre. The degree of exponent, $\lambda$, be 2 . The total type of land use in the studied area, $K$, is set to be 3 types.
We categorize them into 3 different usability types; $k=1$ for business purposes, $k=2$ for retail type, and $k=3$ for residential use. Finally, the total number of stations in the whole transit route, is specified to 18 stations to reflect the current total number of MRT Blue Line stations.

Regarding the land use characteristics, the data are collected in 2015 by the Department of City Planning and Urban Development, the state agency under BMA regulation. In the base case, we sort out the land use data within the 550-metre radius area surrounding the MRT Blue Line station, as it represents the maximum walkable distance to access the nearest station and the potential catchment area of the transit system [25]. However, we must consider only the area types that affect the trip generation/attraction of MRT. Therefore, the area of road, river, expressway, and vacant space are not included in the calculation as shown in Fig. 7. The abbreviations from ST01 to ST-18 are used to denote station names along the inbound direction of the MRT Blue Line from Bang Sue to Hua Lamphong correspondingly.

The correctness of land use data is randomly checked by our survey team and the street view function of Google Map. The verified land use data are then classified according to 3 patterns of trip generation/trip attraction as previously described. We also include the potential of creating actual activities of each building during each period of the day in term of the Gross Floor Area (GFA), which can reflect the usability of the building. For example, the ground floor of shop-houses is allocated for the retail use, while the upper floors are for the residential use. The distribution of each type of land use around all stations of 
MRT Blue Line is shown in Table. 3. Overall, $14.98 \%$ of total catchment area of MRT Blue Line is used for business purposes, $37.10 \%$ for residential use and $47.92 \%$ is the retail area, where people can both live and work here. In conclusion, the total GFA of catchment area surrounding the 18-station of MRT Blue Line are approximately 5,000,000 square metres. The average daily ridership of the MRT Blue Line are approximately 290,000 passengers.
Furthermore, we initiate the scenarios by hypothetically apportioning the land use among three types of land use into 3 categories - Business Oriented Development, Retail Oriented Development, and Residential Oriented Development - in accordance with the land use development tendency. The land use proportion for each scenario is shown in Table 4. Each scenario is supposed to figure out the guideline for the development of some specific types of land use.

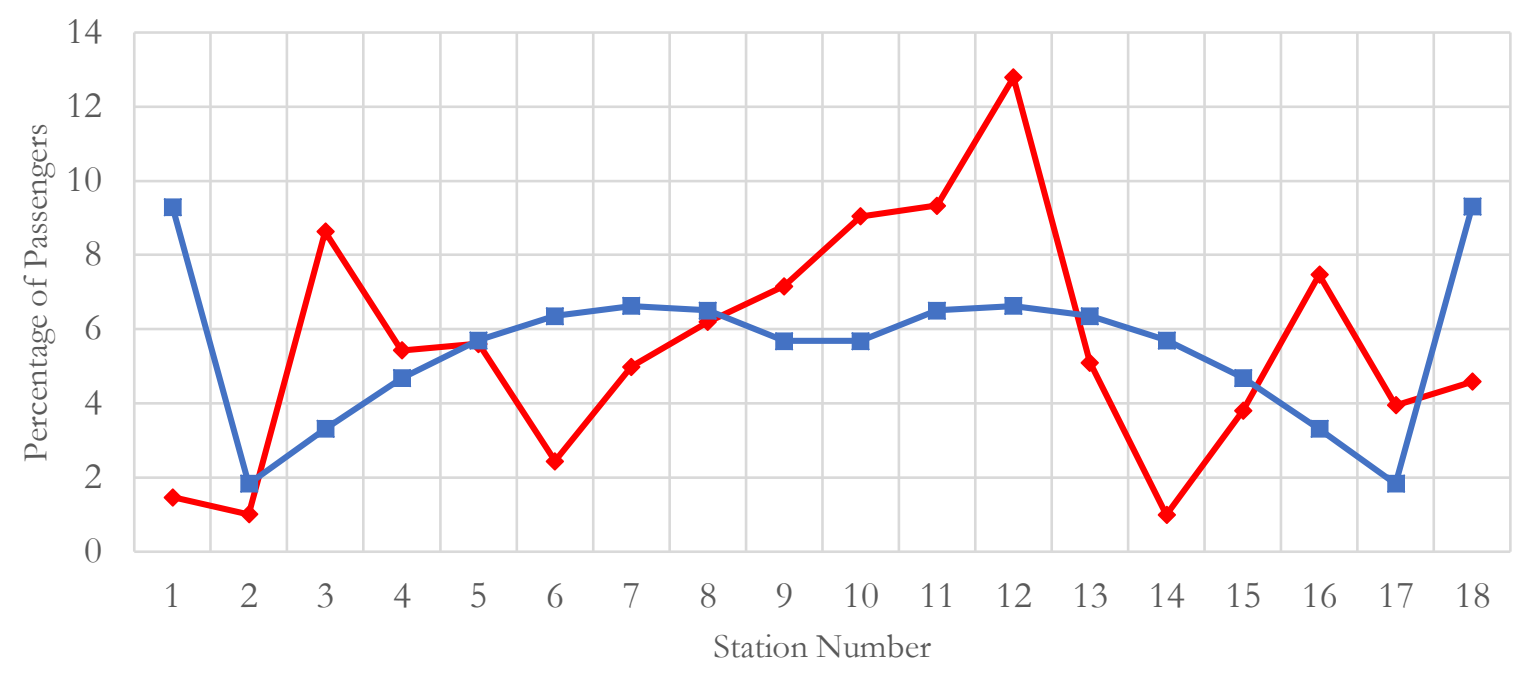

$\longrightarrow$ Existing Optimum

Fig. 6. Distributions of the Number of Passengers Boarding at Each Station for a Case Study of MRT Blue Line (Unit: Percentage).

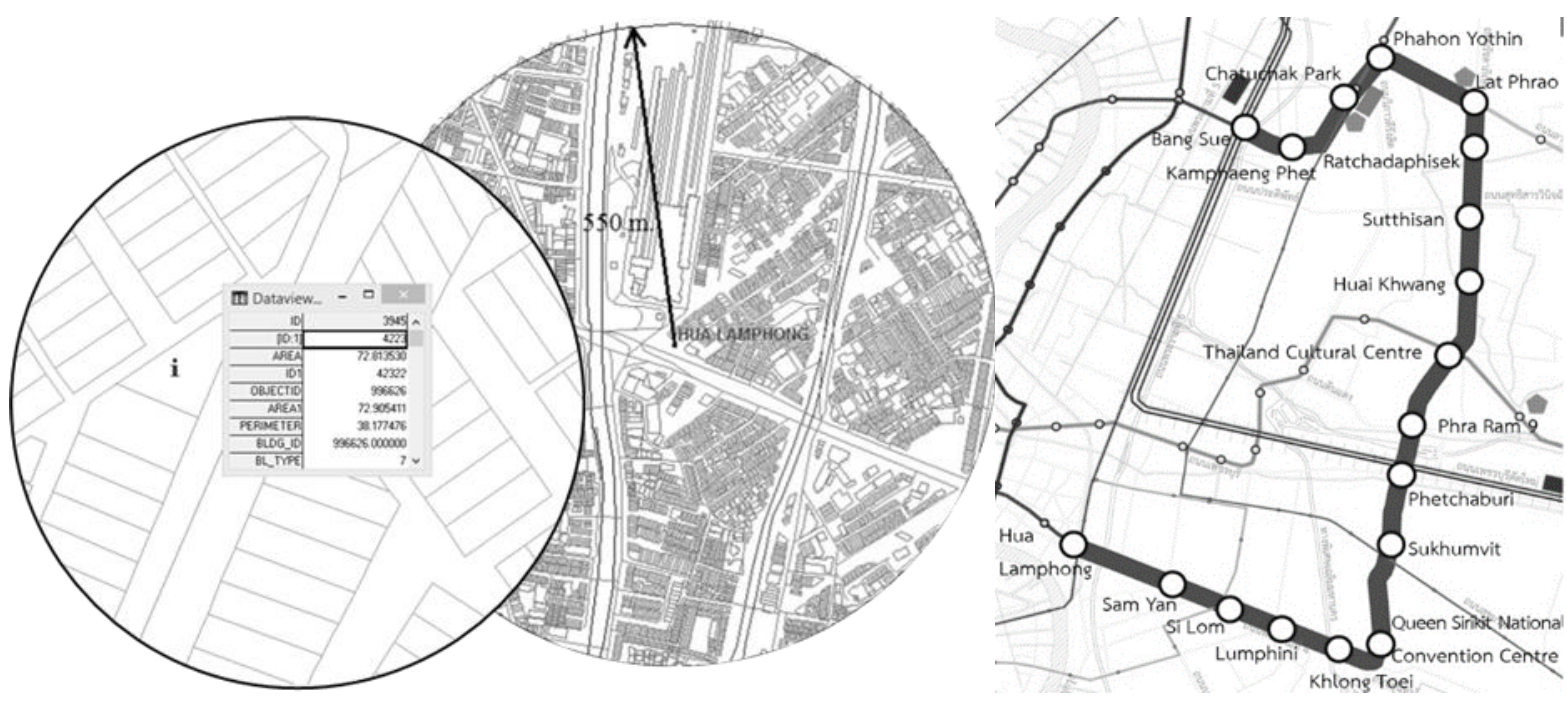

Fig. 7. The categorization of land use surrounding MRT Blue Line. 
Table 3. The existing gross floor area around MRT Blue Line (Unit: 1,000 Square Metre).

\begin{tabular}{rlrrrr}
\hline \hline Station & \multicolumn{1}{c}{ Station Name } & Business & Retail & Residential & Total \\
\hline ST-01 & Bang Sue & 21.55 & 89.87 & 54.19 & 165.60 \\
\hline ST-02 & Kamphaeng Phet & 45.71 & 136.81 & 95.06 & 277.57 \\
\hline ST-03 & Chatuchak Park & 24.01 & 147.71 & 45.62 & 217.34 \\
\hline ST-04 & Phahon Yothin & 47.69 & 127.88 & 77.96 & 253.53 \\
\hline ST-05 & Lat Phrao & 22.73 & 97.21 & 153.41 & 273.34 \\
\hline ST-06 & Ratchadaphisek & 11.92 & 85.30 & 157.42 & 254.64 \\
\hline ST-07 & Sutthisan & 7.75 & 108.05 & 175.86 & 291.66 \\
\hline ST-08 & Huai Khwang & 10.92 & 151.12 & 194.19 & 356.23 \\
\hline ST-09 & Thailand Cultural Center & 10.87 & 181.92 & 73.52 & 266.32 \\
\hline ST-10 & Phra Ram 9 & 2.79 & 182.85 & 145.14 & 330.79 \\
\hline ST-11 & Phetchaburi & 93.93 & 123.23 & 39.09 & 256.25 \\
\hline ST-12 & Sukhumvit & 12.29 & 265.63 & 108.72 & 386.63 \\
\hline ST-13 & Queen Sirikit National Convention Center & 45.53 & 135.38 & 97.81 & 278.72 \\
\hline ST-14 & Khlong Toei & 29.16 & 87.94 & 83.07 & 200.17 \\
\hline ST-15 & Lumphini & 39.76 & 93.39 & 63.01 & 196.17 \\
\hline ST-16 & Si Lom & 112.18 & 130.36 & 65.22 & 307.76 \\
\hline ST-17 & Sam Yan & 141.66 & 119.06 & 70.44 & 331.17 \\
\hline ST-18 & Hua Lamphong & 75.09 & 153.73 & 171.57 & 400.38 \\
\hline \hline Total & $\mathbf{7 5 5 . 5 2}$ & $\mathbf{2 , 4 1 7 . 4 4}$ & $\mathbf{1 , 8 7 1 . 2 8}$ & $\mathbf{5 , 0 4 4 . 2 5}$ \\
\hline \hline & Percentage & $\mathbf{1 4 . 9 8}$ & $\mathbf{4 7 . 9 2}$ & $\mathbf{3 7 . 1 0}$ & $\mathbf{1 0 0 . 0 0}$ \\
\hline \hline
\end{tabular}

Table 4. The land use proportion according to the defined oriented scheme (Unit: percent).

\begin{tabular}{lcccc}
\hline \multirow{2}{*}{\multicolumn{1}{c}{ Scenario }} & \multicolumn{4}{c}{ The percentage of each land use type } \\
\cline { 2 - 5 } & Business & Retail & Residential & Total \\
\hline Base Case (existing MRT Blue Line) & 14.98 & 47.92 & 37.10 & 100 \\
\hline Business Oriented Development & 25 & 40 & 35 & 100 \\
\hline Retail Oriented Development & 10 & 55 & 35 & 100 \\
\hline Residential Oriented Development & 10 & 40 & 50 & 100 \\
\hline
\end{tabular}

The results of the optimal land use allocation for the balanced ridership with the modified FAM from the basecase scenario is shown in Fig. 8. The land use allocation here shows the same pattern as the results derived from the land use allocation problem in the previous section. The residential area is settled into 2 layers where the outer residential zones are located at both ends of the line and the inner zone is located closer to the CBD. The retail areas are consistently spreading in the central part, while the business areas are intensely concentrated in the CBD of the city.

In addition, the results of the land use allocation in other hypothetical scenarios are shown in Table 5 . The objective values of all cases are equal whilst the assigned gross floor area has changed. We can also observe that for the business-oriented development scenario and the retail- oriented development scenario where the proportion of total gross floor for residential uses is equally fixed at 35 units, the results of the distributed proportion of residential area among the 18 stations are equal, station by station.

Meanwhile, the distribution pattern of other types is also similar as previously explained. We can hence conclude that the land use distribution remains the same pattern, even if the proportion has changed. Interestingly, the all allocation patterns have the same level of variance, which is the optimal degree of balanced ridership. Therefore, the land use along the MRT transit route can possibly be allocated to achieve the highest balance of ridership, in despite of the land use control regulations from the government that limit the development planning. 


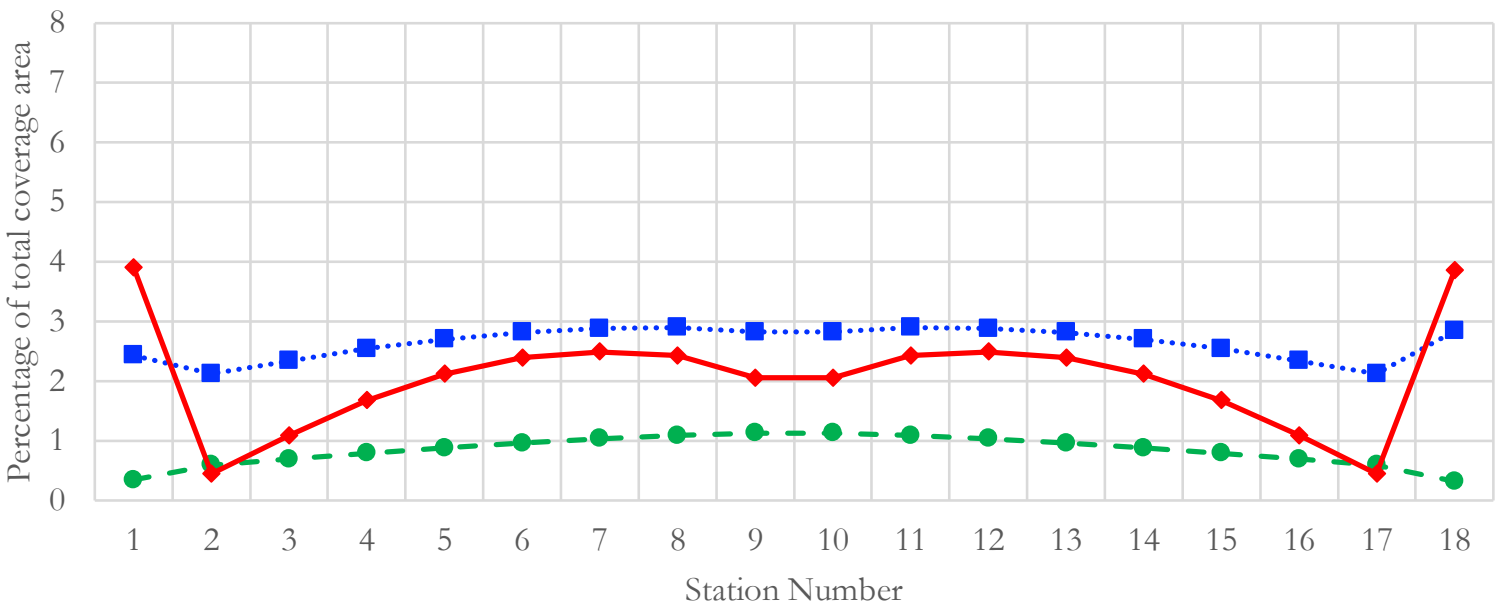

- - Business …… Retail $\longrightarrow$ Residential

Fig. 8. The land use allocation result of base case (the MRT Blue Line) (Unit: percent).

Table 5. Allocation of land use to balance O-D ridership for each scenario (Unit: percent).

\begin{tabular}{|c|c|c|c|c|c|c|c|c|c|}
\hline \multirow[b]{2}{*}{ ST. } & \multicolumn{3}{|c|}{$\begin{array}{l}\text { Business (Bus.) } \\
\text { Oriented Development }\end{array}$} & \multicolumn{3}{|c|}{$\begin{array}{c}\text { Retail (Ret.) } \\
\text { Oriented Development }\end{array}$} & \multicolumn{3}{|c|}{$\begin{array}{c}\text { Residential (Res.) } \\
\text { Oriented Development }\end{array}$} \\
\hline & Bus. & Ret. & Res. & Bus. & Ret. & Res. & Bus. & Ret. & Res. \\
\hline ST-01 & 0.57 & 2.03 & 3.69 & 0.24 & 2.80 & 3.69 & 0.24 & 2.03 & 5.28 \\
\hline ST-02 & 0.99 & 1.77 & 0.43 & 0.40 & 2.45 & 0.43 & 0.40 & 1.77 & 0.61 \\
\hline ST-03 & 1.17 & 1.96 & 1.03 & 0.47 & 2.70 & 1.03 & 0.47 & 1.96 & 1.47 \\
\hline ST-04 & 1.32 & 2.12 & 1.59 & 0.53 & 2.93 & 1.59 & 0.53 & 2.12 & 2.27 \\
\hline ST-05 & 1.48 & 2.26 & 2.00 & 0.59 & 3.11 & 2.00 & 0.59 & 2.26 & 2.86 \\
\hline ST-06 & 1.61 & 2.35 & 2.26 & 0.65 & 3.24 & 2.26 & 0.65 & 2.35 & 3.23 \\
\hline ST-07 & 1.73 & 2.41 & 2.36 & 0.70 & 3.32 & 2.36 & 0.70 & 2.41 & 3.36 \\
\hline ST-08 & 1.83 & 2.42 & 2.29 & 0.73 & 3.34 & 2.29 & 0.73 & 2.42 & 3.28 \\
\hline ST-09 & 1.89 & 2.36 & 1.95 & 0.76 & 3.25 & 1.95 & 0.76 & 2.36 & 2.77 \\
\hline ST-10 & 1.89 & 2.36 & 1.95 & 0.76 & 3.25 & 1.95 & 0.76 & 2.36 & 2.77 \\
\hline ST-11 & 1.83 & 2.42 & 2.29 & 0.73 & 3.34 & 2.29 & 0.73 & 2.42 & 3.28 \\
\hline ST-12 & 1.73 & 2.41 & 2.36 & 0.70 & 3.32 & 2.36 & 0.70 & 2.41 & 3.36 \\
\hline ST-13 & 1.61 & 2.35 & 2.26 & 0.65 & 3.24 & 2.26 & 0.65 & 2.35 & 3.23 \\
\hline ST-14 & 1.48 & 2.26 & 2.00 & 0.59 & 3.11 & 2.00 & 0.59 & 2.26 & 2.86 \\
\hline ST-15 & 1.32 & 2.12 & 1.59 & 0.53 & 2.93 & 1.59 & 0.53 & 2.12 & 2.27 \\
\hline ST-16 & 1.17 & 1.96 & 1.03 & 0.47 & 2.70 & 1.03 & 0.47 & 1.96 & 1.47 \\
\hline ST-17 & 0.99 & 1.77 & 0.43 & 0.40 & 2.45 & 0.43 & 0.40 & 1.77 & 0.61 \\
\hline \multirow[t]{2}{*}{ ST-18 } & 0.55 & 2.37 & 3.63 & 0.22 & 3.26 & 3.63 & 0.22 & 2.37 & 5.20 \\
\hline & 25.16 & 39.70 & 35.14 & 10.12 & 54.74 & 35.14 & 10.12 & 39.70 & 50.18 \\
\hline Variance & \multicolumn{3}{|c|}{10.026} & \multicolumn{3}{|c|}{10.026} & \multicolumn{3}{|c|}{10.026} \\
\hline
\end{tabular}

\subsection{The Effects of Mixed-Use Project Development on the Ridership Balance}

Nowadays, many mixed-use projects are initiated along the mass transit line of Bangkok. The idea is that the mixed-use project can be developed alongside the mass transit project as they have a potential to support each other. However, some factors of the mixed-use project may have a negative effect on the ridership balance depending on the location of the project and the area of each type of land use. In this section, we investigate the effects of the mixed-use project development on the balance of ridership by the case study of the subway system in Bangkok, Thailand.

Many mixed-use projects are in the process of development along the MRT Blue Line route, such as the Sam Yan Mitrtown project, the One Bangkok project, the Dusit Thani - CPN project, the FYI center project, the PARQ project, the Bang Sue Grand Station project [26, $27,28]$. The development plan of these projects regarding the area of each usable type, the location of project along the route, the mixing proportion of each type, should be carefully examined to encourage the capability for both the transit system and the mixed-use project. For our specific 
case study, we choose the Sam Yan Mitrtown project as the example to verify its effects on the ridership balance of the MRT Blue Line through the modified FAM model.

The "Sam Yan Mitrtown" project, as shown in Fig. 9, is located at the corner of Phayathai - Rama 4 Road, Pathumwan, Bangkok and connected to Sam Yan Station of the MRT Blue Line. It covers 3 zones as follows:

(1) The Mitrtown office tower; a 31-storey Grade A office building with approximately $45 \%$ of the project's usable space, which is designed under the theme of "Intelligent Office Tower" and developed under the concept of "Smart \& Friendly" with the total office space from the $7^{\text {th }}$ floor to $31^{\text {st }}$ floor and the exhibition hall from the $5^{\text {th }}$ floor to $6^{\text {th }}$ floor,
(2) The residential tower; the 33-floor residential zone covering $20 \%$ of the project's usable space, which consists of a hotel and a condominium from the $7^{\text {th }}$ floor to $33^{\text {rd }}$ floor, and

(3) The retail zone; the 6-floor retail with approximately $35 \%$ of the project's usable space, which is designed under the concept of "learning is possible in a friendly environment" with a co-learning space, a supermarket, restaurants, cafe, and a cinema zone.

The scheme has been completed in September 2019. The gross floor area (GFA) covers approximately 210,000 square metres and can be categorized into 3 useable area types — business, retail, and residential — as shown in Table 6.

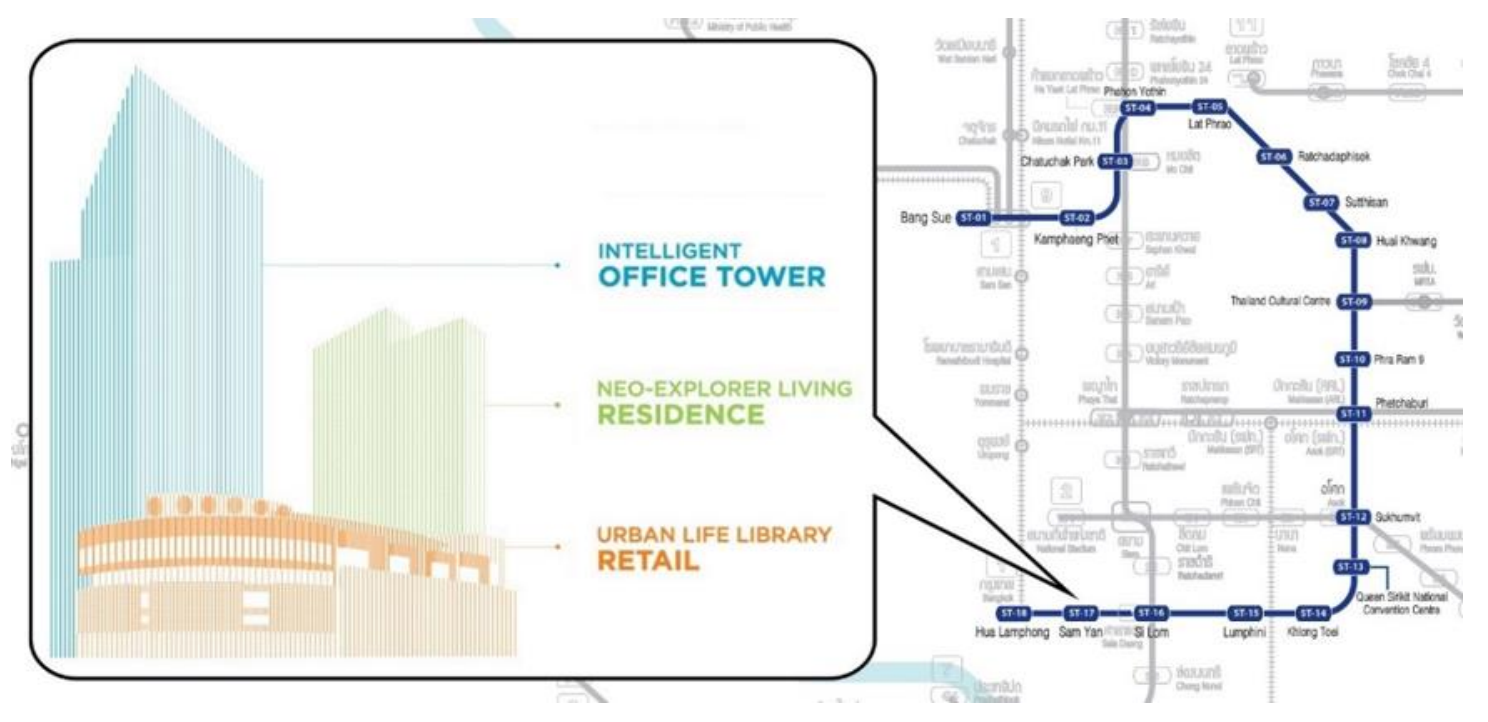

Fig. 9. The Sam Yan Mitrtown Project which connected to the Sam Yan station of MRT Blue Line (modified from www.samyan-mitrtown.com).

Table 6. The Gross Floor Area of Developing Project (Sam Yan Mitrtown) (Unit: 1,000 Square Metre).

\begin{tabular}{lccccc}
\hline \multirow{2}{*}{ Project } & \multicolumn{4}{c}{ The GFA of each land use type } \\
\cline { 2 - 5 } & Business & Retail & Residential & Total \\
\hline \hline Sam Yan Mitrtown & 96 & 72 & 42 & 210 \\
\hline
\end{tabular}

Here, we examine the effects of the Sam Yan Mitrtown project on the balance of ridership by assuming that this project can be located at any station of the MRT Blue Line. The land use proportion for the targeted station is then updated accordingly. In the meantime, the GFA for other stations are remained the same. Finally, the objective value expressed by the variance of onboard ridership can then be investigated on a case-by-case basis. The effects of the Sam Yan Mitrtown project development on the balance of ridership are shown in Table 7 . We can observe that the location of this project has the distinguish effects on the balance of ridership of the whole transit system. When we apply GFA of the Sam Yan Mitrtown project to either station $1,2,3,4,9,10,11,12,13$ or 14 , it reflects the lower variance of onboard ridership as compared to the present situation where its variance is 12.638.
It can be implied from these results that the location of the project is the factor that influences the balance of ridership. If the project we develop is prudently located at some exact stations, it would alleviate the balance of ridership. On the other hand, if the project is misplaced to some other stations, the situation might be deteriorated. As a result, the mixed-use project development planning should take into account the overall perspective, especially the impacts on the surrounding mass transit system. Moreover, the investigation for the observed data of trip generation and trip attraction rate is also essential when putting our model in real practice. Nevertheless, we believe that the results presented here could be used as the guideline for land use development planning to support the mass transit system efficiently. 
Table 7. The variance of onboard ridership in case of the Sam Yan Mitrtown implementation (Unit: Square of percentage of total passengers).

\begin{tabular}{lccccccccc}
\hline \hline Station & ST-01 & ST-02 & ST-03 & ST-04 & ST-05 & ST-06 & ST-07 & ST-08 & ST-09 \\
\hline \hline Variance & $\mathbf{1 1 . 2 0 1}$ & $\mathbf{1 2 . 1 2 7}$ & $\mathbf{1 2 . 3 3 5}$ & $\mathbf{1 2 . 5 4 0}$ & 12.757 & 12.853 & 12.921 & 12.892 & $\mathbf{1 2 . 6 0 5}$ \\
\hline Station & ST-10 & ST-11 & ST-12 & ST-13 & ST-14 & ST-15 & ST-16 & ST-17 & ST-18 \\
\hline \hline Variance & $\mathbf{1 2 . 4 8 9}$ & $\mathbf{1 2 . 2 1 4}$ & $\mathbf{1 2 . 2 6 3}$ & $\mathbf{1 2 . 3 2 0}$ & $\mathbf{1 2 . 4 9 2}$ & 12.877 & 13.486 & 14.023 & 14.118 \\
\hline
\end{tabular}

\section{Concluding Remarks}

In this study, the modified FAM is applied to cope with a land use consideration. The objective of the study is to minimize the variations of onboard passengers between any adjoining stations both for outbound and inbound directions along the single train line by allocating each type of the land use around each station. Assuming that each type of land use has generated and attracted person trips at different rates, this study has revealed the optimal proportion of land use around the transit station and furthered applied the proposed model to verify the effects of the ongoing real estate projects along the MRT Blue Line of Bangkok on its ridership. Such projects are a significant factor that has a considerable impact on transit passengers as they generate many activities that attract people and bring people to/from that area. To simplify our analysis, the types of land use around transit stations are categorized into three major types with different trip generation and trip attraction rates.

To balance transit ridership, the results show that the requirements of land use allocation along a transit route are: 1) The residential areas should be densely located at the terminal stations. In case of the long mass transit route with more than 12 stops, the sub-residential areas should also be located in the interval in order to shorten the distance of home-based trip; 2) The business areas should be densely located in the middle of mass transit route; and 3) The retail area should be dispersedly located all along the route. Even though this paper only shows the evidence in allocating three types of land use to balance the transit ridership for up to 18 stations, the results in the case of higher numbers of transit stations tend to be similar.

The mixed-use project and the mass transit line have a potential to support each other by increasing the accessibility. The land use development factors such as centricity, density and mix can affect the accessibility of public transport [29]. Therefore, many mixed-use projects are currently initiated along the mass transit line. By investigating the impact of mixed-use project development on the ridership balance, the results show that the location of the project significantly influences the balance of ridership. The land use planning development and traffic demand management associated with the public Transportation Oriented Development (TOD) principle are among the several factors that help solve the unbalanced ridership of mass transit system and organise the optimal capacity of transit system for the long-term growth.

Mass transit lines operate not only during the AM and PM peak hours but the operation during the off-peak hours also face a similar problem of unbalanced ridership. The future analysis should be conducted to find patterns of land use that can minimize the variations of ridership along the route in all operating hours. In addition, it is interesting to see how different pattern and more complex mass transit networks, e.g., intersecting or circular lines, can achieve the balance ridership by the land use development. The research regarding these issues is in progress. The study of this kind would bring a better understanding of the land use development and the transit ridership modeling. It would also be the guideline both for more sustainable land use and mass transit development.

\section{References}

[1] Institute of Transportation Engineers, Trip Generation User's Guide, 8th ed. Washington, D.C., 2008.

[2] X. Wang and R. Hofe, "Land use analysis," in Research Methods in Urban and Regional Planning. Beijing; Berlin Heidelberg: Tsinghua University Press; Springer-Verlag GmbH, 2007.

[3] B. D. Taylor and C. N Y Fink, "The factors influencing transit ridership: A review and analysis of the ridership literature," UCLA Institute of Transportation Studies, L.A., 2003.

[4] C. A Hendrickson, "A note on trends in transit commuting in the United States relating to employment in the central business district," Transportation Research Part A, vol. 20A, no. 1, pp. 33 - 37, Jan. 1986.

[5] Nelson and Nygaard Consulting Associates, Land Use and Transit Demand: The Transit Orientation Index. Portland, OR, 1997.

[6] B. Pushkarev and J. M. Zupan, Public Transportation and L and Use Policy. Bloomington: Indiana University, 1977.

[7] R. J. Spillar and G. S. Rutherford, "The effects of population density and income on per capita transit ridership in western American cities," in Institute of Transportation Engineers Compendium of Technical Papers: 60th Annual Meeting, 1990, pp. 327 - 331. 
[8] R. Crane "The influence of urban form on travel: An interpretive review," Journal of Planning Literature, vol. 15 , no. 1 , pp. $1-22,2000$.

[9] C. Saksith, "Transportation development and urbanization in the Bangkok Metropolitan Region," in Routledge Handbook of Urbanization in Southeast Asia, 2019 , pp. $288-306$.

[10] J. J. Lin and A. T. Yang, "Structural analysis of how urban form impacts travel demand: Evidence from Taipei," Urban Studies, vol. 46, no. 9, pp. 1951 - 1967, 2009.

[11] N. Hu, E. F. Legara, K. K. Lee, G. G. Hung, and C. Monterola, "Impacts of land use and amenities on public transport use, urban planning and design," Land Use Policy, vol. 57, pp. 356-367, 2016.

[12] Transportation Research Board of The National Academies, "Elements needed to create high ridership transit systems," TCRP Report 111, Washington, DC, 2007.

[13] The Institute of Transportation Engineers, The Trip Generation Manual, 10 th ed. Washington DC: Institute of Transportation Engineers, 2017. [Online]. Available: https://www.ite.org/tripgeneration. [Accessed: 26 July 2017]

[14] X. Wang and R. Hofe, Research Methods in Urban and Regional Planning. Germany: Springer-Verlag 2007.

[15] The City of San Diego, "Trip generation rate summary," in Trip Generation Manual. CA: The City of San Diego, California, 2017.

[16] J. D. Ortuzar and L. G. Willumsen, "Trip distribution modelling," in Modelling Transport, $4^{\text {th }}$ ed. New Jersey: Wiley, 2011, ch. 5, sec. 3.

[17] B. Samanta and S. K. Mazumder, "The constrained gravity model with power function as cost function," Journal of Applied Mathematics and Decision Sciences, Article ID 48632, pp. 1-13, 2006.

[18] I. Hong and W.S. Jung, "Application of gravity model on the Korean urban bus network," Physica $A$, vol. 462, pp. 48-55, 2016.

[19] M. Stefanouli and S. Polyzos, "Gravity vs Radiation model: two approaches on commuting in Greece," Transportation Research Procedia, vol. 24, pp. 65-72, 2017.
[20] P. Bunditsakulchai, A. Limmonthol, and J. Rudjanakanoknad, "Balancing mass transit ridership through land use development," in Proceeding of Transportation Research Board Annual Meeting, 2018, Paper Number: 18-04385.

[21] S. Tsygalnitzky, "Simplified methods in transportation analysis," dissertation, Civil Engineering Dept, Massachusetts Institute of Technology, Cambridge, MA, 1977.

[22] X. Hu and Y. Zhang, "The application of fluid analogy method for estimating transit route ODs using IC card on-off passenger data;" Applied Mechanics and Materials, vol. 694, pp. 73-79, 2014.

[23] Y. Liao and C. Lin, "The modification of fluid analogy method for O-D estimation on highway corridors," in 2nd International Conference on Electric Technology and Civil Engineering, Hubei, China, 2012, pp. 3248 - 3251.

[24] Y. Liao and C. Lin, "The verification of TDFAM using freeway flow counts," in International Conference on Remote Sensing, Environment and Transportation Engineering, Nanjing, China, July 2013, pp. 517-520.

[25] R. Cervero, “Transit oriented development's ridership bonus: A product of self-selection and public policies," Environment and Planning A, vol. 39, pp. 2068-2085, 2007.

[26] S. Srimalee. (2018). Bang Sue Station Tipped as Bt150 $\mathrm{Bn}$ Investment Magnet [Online]. Available: https://www.nationthailand.com/Economy/30344 983 [Accessed: 24 December 2018]

[27] Fresh Editorial. (2018). Rama 4 Road a New CBD in the Making? [Online]. Available: https:// freshbangkok.com/rama-4-road-new-cbdmaking/ [Accessed: 24 December 2018]

[28] Tunyawit. (2019). Bang Sue Grand Station, The Biggest Transportation Hub in Southeast Asia [Online]. Available:

http:// aboutthailandliving.com/2019/04/01/bangsue-grand-station-the-biggest-transportation-hubin-southeast-asia/ [Accessed: 6 May 2019]

[29] T. Litman, "Evaluating accessibility for transport planning measuring people's ability to reach desired goods and activities," Victoria Transport Policy Institute, Victoria, Canada, 2019.

Achara Limmonthol, photograph and biography not available at the time of publication.

Jittichai Rudjanakanoknad, photograph and biography not available at the time of publication.

Pongsun Bunditsakulchai, photograph and biography not available at the time of publication. 